\title{
KAIRÓS DOLOROSO Y ABURRIMIENTO: ESPERAR POR EL PRECISO MOMENTO
}

\author{
Reynaldo Padilla-Teruel \\ doi: 10.11144/Javeriana.uph35-71.kdae
}

\section{RESUMEN}

En este artículo se reflexiona sobre el fenómeno de la espera, interpretado en nuestro propio contexto, pero a partir de un texto de Heidegger. En el mismo se implica que el aburrido espera por el preciso momento de algo de lo cual presume que disipará su aburrimiento. Se procederá a mostrar la estructura interna del tiempo-experiencia del fenómeno de la espera que se experimenta cuando estamos aburridos y cómo el devenir de este tiempo se configura existencialmente en dolor. Para ello, se indagará fenomenológicamente la estructura temporal de tal espera, indicando así cómo dicha estructura transforma la existencia de quien espera aburridamente.

Palabras clave: acontecer; devenir; kairología; insuficiencia vital; aburrimiento in extremis

Universidad Carlos III, Madrid, España. Pontificia Universidad Javeriana, Bogotá, Colombia. Correo electrónico: 100344169@alumnos.uc3m.es

Para citar este artículo: Padilla-Teruel, R. (2018). Kairós doloroso y aburrimiento. Esperar por el preciso momento. Universitas Philosophica, 35(71), pp. 295-321. ISSN 0120-5323 0120-5323, ISSN en línea 2346-2426. doi: 10.11144/Javeriana.uph35-71.kdae 


\title{
PAINFUL KAIRÓS AND BOREDOM: WATING FOR THE RIGHT TIME
}

\begin{abstract}
In this article we reflect on the phenomenon of waiting, interpreted in our own context, but drawn from a text by Heidegger. The text implies that the bored person is waiting for the moment in which something will, as they presume, dissipate their boredom. We will proceed to show the internal structure of time as a lived experience of the phenomenon of waiting while bored, and how this time is existentially configured as pain. To do this, the temporal structure of such waiting will be examined phenomenologically to demonstrate how it transforms the existence of whoever is waiting while bored.

Keywords: event; becoming; kairology; vital insufficiency; boredom in extremis
\end{abstract}


En la espera se manifiesta, se revela, la esencia del tiempo.

¿Que superioridad la de haber dejado de esperar!

Cioran, Cuadernos (1957-1972), p. 85.

EN SU LECCIÓN DE 1929-1930 titulada Los conceptos fundamentales de la metafisica: mundo, finitud, soledad, Heidegger (2015) afirma que "el aburrimiento sólo es posible en general porque toda cosa, como decimos, tiene su tiempo" (p. 142). Si cada cosa tiene su preciso momento, surgen aquí dos implicaciones. Primero, se ha de examinar el aburrimiento como aquello que se produce en tanto se espera porque cada cosa sea en su preciso momento. Segundo, es necesario reflexionar sobre lo que aquí llamamos "dolor existencial"; esto es, la añoranza que se sufre a causa de que las cosas son a su propio tiempo y no al nuestro; es decir, de que las cosas no son justamente aquí en nuestro ahora cuando las deseamos o necesitamos. En este sentido, se presenta la tesis de que el aburrimiento puede ser entendido como aquello que da paso al dolor existencial mediante la espera. El aburrido espera por el preciso momento de algo que, presume, disipará su aburrimiento. La manifestación del tiempo en este esperar no se da necesariamente en su forma de transcurrir en momentos sucesivos, que auguran la cercanía de aquello por lo que se aguarda, sino que se manifiesta en una kairología o kairosofía ${ }^{1}$. Esto es el tiempo "interno" de aquello que contiene en sí mismo su propio devenir. Entonces, la espera por el momento preciso de algo se torna en

1 Para trabajar con este concepto, nos apoyamos en la obra del filósofo Manfred Kerkhoff titulada Kairos (1997), donde se acuñan estos términos. Con ellos se hace referencia a: "cómo un momento prácticamente inextenso puede, no obstante, contener el peso de toda una existencia. [...] El instante vivido como 'lugar' de una posible libertad, nos propicia una abertura hacia algo que se encuentra en una dimensión transversal al mero transcurrir del tiempo; en otras palabras: el instante como punto de partida de una acción o decisión (como lugar de empezar, y resolver), nos sitúa en una dimensión 'vertical' que es típica de todo lo que se origina, nace, crece, y se distingue de la dimensión 'horizontal' del transcurrir como el saltar del correr. [...] El tema propuesto en este trabajo se refiere a las gradaciones del instante vivido, y va desde el instante normal, cotidiano, apenas advertido, ascendiendo a momentos decisivos, como el llamado momento 'justo' o 'fatal', para culminar en los momentos de carácter cuasi-místico, momentos de consumación, triunfo, felicidad, éxtasis, etc." (Kerkhoff, 1997, pp. 1-3). 
un aguardar kairológico. A continuación, se mostrará la estructura interna del tiempo como vivencia del fenómeno de la espera que se experimenta cuando estamos aburridos y cómo el devenir de este tiempo se configura existencialmente en dolor. Para ello, se indagará la estructura temporal de tal espera y se indicará cómo dicha estructura transforma la existencia de quien espera aburridamente.

\section{Aquello por lo que se espera}

Dentro de sus múltiples aCEPCIONES, el aburrimiento se puede entender como un tipo de espera. Sobre todo, si tenemos en cuenta la cita de Heidegger con la que iniciamos el presente texto, de inmediato nos percatamos que en ella se apunta a una manera peculiar de darse el tiempo en la espera. Antes de volver de lleno a la cita referida, mencionemos los ejemplos que Heidegger utiliza para explicar los tres niveles de aburrimiento en Los conceptos fundamentales de la metafísica. Aunque no se entre aquí en una discusión sobre las tres formas de aburrimiento, vale aclarar que, para Heidegger, el aburrimiento tiene sus raíces en el tiempo, lo que significa que en la medida en que se pretende indagar sobre la esencia del aburrimiento, se indaga también sobre la esencia del tiempo. Tiempo que se presenta de una manera diferente en cada una de las tres formas de aburrimiento descritas por el filósofo.

Primeramente, recordemos que el aburrimiento es para Heidegger (2015) un temple anímico (Stimmung) de nuestro momento histórico ${ }^{2}$ que hay que

2 En este texto del 1929-30, a diferencia de Ser y tiempo, Heidegger “trata” el aburrimiento desde su dimensión histórico-temporal, en el sentido de que en su demostración del fenómeno se plantea como una condición de la época actual. Para ello, Heidegger trae a su argumento la tesis de Oswald Spengler. Citemos: “¿pero qué temple de ánimo hay que despertar para nosotros hoy? Sólo podemos responder esta pregunta si conocemos suficientemente nuestra propia situación, para obtener de ahí el temple de ánimo fundamental que nos rige. [...] La interpretación más conocida de nuestra situación, que ha enardecido en breve tiempo, ha venido a ser aquella que se expresa en el lema 'decadencia de Occidente' (término acuñado por O. Spengler en su obra Der Untergang des Abendlandes) [...]. Expresado en una fórmula, es esto: decadencia de la vida en y mediante el espíritu. Lo que el espíritu, sobre todo como razón (ratio), se configura y ha creado en la técnica, la economía y el tráfico mundial, en toda reconfiguración de la existencia, simbolizado en la gran ciudad, se vuelve contra el alma, contra la vida, y la oprime y fuerza a la cultura a la decadencia y el desmoronamiento" (Heidegger, 2015, p. 101). 
despertar en nosotros; y si hay que despertarlo, es porque ya está de alguna manera en nosotros.

El despertar es un dejar ser al temple de ánimo que antes, manifiestamente, duerme, si nos es permitido emplear esta imagen primeramente en correlación con el uso lingüístico. El temple de ánimo, en cierto sentido, es ahí y el no-ser ahí tiene un carácter peculiar y que en modo alguno coincide con la diferencia entre el estar presente y el no estar presente de una piedra. El no estar presente de la piedra no es un modo determinado de su estar presente, sino lo absolutamente opuesto. Por el contrario, el estar-fuera, la ausencia en sus diversas formas, no es por ejemplo el opuesto excluyente de la existencia, sino al contrario: todo estar-fuera presupone el ser-ahí (p. 96).

Esto significa que Heidegger no nos invita a aburrirnos, sino justamente a despertar el temple anímico que el aburrimiento inherente al hombre contemporáneo trata de ocultar mediante ocupaciones y entretenimiento. Se debe aquí resaltar también que, si Heidegger va detrás del temple anímico del aburrido como un ser aburrido, eso que aburre pasa entonces a ser solamente aquello que despierta el temple anímico que él quiere indagar como disposición de ánimo fundamental de nuestra época. Dicho en otras palabras, lo importante para Heidegger es cómo somos cuando estamos aburridos y no aquello que nos hace ser aburridos. En este sentido, cada ejemplo que da Heidegger para hablar de las distintas formas de aburrimiento resalta el temple anímico del Dasein en esa peculiar situación descrita.

Dice Heidegger (2015):

Los temples de ánimo son los modos fundamentales en los que nos encontramos de tal y cual modo. Los temples de ánimo son el cómo conforme al cual uno se encuentra de tal y cual modo. Cierto que este "a uno le va de tal y cual modo" -por motivos que no hay que explicar ahora- lo tomamos a menudo como algo indiferente frente a aquello que nos proponemos, frente a aquello con lo que estamos ocupados, que sucede con nosotros. Y sin embargo este "uno se encuentra de tal y cual modo" nunca es sólo la consecuencia y un fenómeno que acompaña a nuestro pensar y modo de obrar, sino -dicho a grandes rasgos- el presupuesto de ellos, el "medio" en el que aquéllos suceden por vez primera. [...] Los temples de ánimo son el "presupuesto" y el "medio" 
del pensar y el actuar. Esto significa que se remontan más originalmente en nuestra esencia, que sólo en ellos nos alcanzamos a nosotros mismos: como un ser-ahí (pp. 98-99).

Ya aclarado que a Heidegger le interesa el cómo de nuestro ser-ahí en cada forma de aburrimiento, tenemos como la primera forma de aburrimiento al 'aburrirse por' algo, el cual Heidegger explica mediante el ejemplo de quien espera por el tren en una terminal. Imaginemos que llegamos unas horas antes de que nuestro tren llegue. Durante esas horas de espera, no hay nada qué hacer para "pasar el tiempo". En este caso, estamos atados a la situación aburrida, uno se aburre por la espera. El constante mirar el reloj asume el papel de gesto de querer mover el tiempo rápidamente hacia delante.

Luego, tenemos el 'aburrirse en' una situación particular y que a esta situación le pertenezca el tiempo. Aquí el ejemplo explicativo es una cena entre amigos. Uno "saca tiempo" para ello específicamente, para la cena, pero este tiempo es un tiempo reservado para nada. En la cena uno charla amenamente, uno disfruta la comida, uno se fuma un cigarro; en fin, uno llega a decir que la velada estuvo estupenda, que se pasó de maravilla. Pero uno pregunta: ¿Qué se logró en la cena? ¿Qué de edificante tuvo esta? Pues... nada. El tiempo durante la cena es uno que, contrario al esperar del tren, no nos oprime ni nos ata a la situación, más bien, nos libera de la preocupación por su duración; lo que permite que disfrutemos de la cena sin que el tiempo sea un problema o algo que nos ocupe. Pero hay que reconocer que, aunque el tiempo no nos ocupe, tampoco nos ocupa algo en particular de la cena; por ello, uno se aburre en esta, aunque no haya sentido el peso del tiempo.

Por último, tenemos al aburrimiento profundo como 'uno se aburre'o 'eso aburre' y lo característico de este tercer nivel de aburrimiento es que su porqué es indeterminado, lo que en la terminología heideggeriana se denomina inauténtico. El aburrimiento profundo consume al "uno" inauténtico, pues "para este aburrimiento falta el pasatiempo" (Heidegger, 2015, p. 177); lo que significa que no hay un sujeto particular que se relacione originariamente con esta experiencia. Lo propio del universal es que no es de nadie, sino de todos, pero de ninguno particularmente ${ }^{3}$.

3 Sobre esta indeterminabilidad, Heidegger también habla en Ser y tiempo, cuando analiza el quién del Dasein: "el uno está en todas partes, pero de tal manera que ya siempre se ha escabullido de allí donde la existencia urge a tomar una decisión. Pero, como el uno ya ha anticipado siempre todo 
"Es" es el título para lo indeterminado y desconocido. Pero después de todo lo conocemos, y lo conocemos como perteneciente a la forma más profunda del aburrimiento: lo que aburre. Es: el propio sí mismo abandonado que cada uno es por sí mismo [...], del que decimos que yo me aburro, tú te aburres, nosotros nos aburrimos (Heidegger, 2015, p. 176).

En la primera forma de aburrimiento existe un vínculo de atadura con el tiempo hacia eso que causa el aburrimiento, justamente porque es el tiempo mismo quien nos ata a la situación que nos produce el aburrimiento. En la segunda forma hay un relativo liberarse del tiempo, esto porque el tiempo es "quien" nos libera hacia la situación que nos aburre, en el sentido de que el tiempo que trascurre nos abandona en su transcurrir en cuanto a la duración de la situación dada. En la tercera, cuando nos atrapa en su forma más profunda, el aburrimiento tiende a "liberarnos" del tiempo en su forma de duración general. Ya no es que nos libera hacia la situación aburrida, sino que esta liberación, según Heidegger, nos deja vacíos; y nos sentimos vacíos, porque el tiempo nos abandona (Leergelassenheit).

Según Heidegger va desarrollando su filosofar en torno al aburrimiento, muestra el alejamiento del tiempo en su forma de transcurrir, para acercarse al tiempo oportuno del kairós (kalpós). Las tres formas de aburrimiento en Heidegger son no más que estadios temporales en los cuales nos adentramos a un aburrimiento profundo, donde el tiempo se transforma y nos transforma.

La cita completa de Heidegger con la que comenzamos nuestro texto reza así:

$\mathrm{Si}$, evidentemente, las cosas tienen respectivamente su tiempo, y si nosotros damos con las cosas respectivamente a su tiempo, entonces tal vez no se produzca el aburrimiento. Dicho al revés: el aburrimiento sólo es posible en

juicio y decisión, despoja, al mismo tiempo, a cada Dasein de su responsabilidad. El uno puede, por así decirlo, darse el lujo de que constantemente 'se' recurra a él. Con facilidad puede hacerse cargo de todo, porque no hay nadie que deba responder por algo. Siempre 'ha sido' el uno y, sin embargo, se puede decir que no ha sido 'nadie'. En la cotidianidad del Dasein la mayor parte de las cosas son hechas por alguien de quien tenemos que decir que no fue nadie. Así el uno aliviana al Dasein en su cotidianidad. Pero no sólo eso: con este alivianamiento del ser, el uno satisface los requerimientos del Dasein, en tanto que en éste se da la tendencia a tomar todo a la ligera y a hacer las cosas en forma fácil. Y puesto que el uno con el alivianamiento del ser satisface constantemente los requerimientos del Dasein, mantiene y refuerza su porfiado dominio" (Heidegger, 1997, p. 152). 
general porque toda cosa, como decimos, tiene su tiempo. Si cada cosa no tuviera su tiempo, entonces no habría aburrimiento (Heidegger, 2015, p. 142).

A partir de la cita se dice que, si bien las cosas tienen su tiempo, su preciso momento, no queda pues que aburrirse hasta que tal tiempo sea y me involucre en su acontecer. Se espera por el mutuo coincidir entre aquello que en sí mismo lleva su propio ritmo con el ritmo de mi ser en el mundo. Sufrimos un aburrimiento en forma de espera como quien quiere arrastrar a la existencia aquello no existente que calmará el dolor de la demora. Preguntamos entonces: ¿qué es aquello por lo que el aburrido espera? Pero antes de interpretar la pregunta en su sentido específico y peculiar, que indaga "qué es eso inexistente por lo cual esperamos", pensemos en que lo que se desea aclarar por ahora es: ¿qué significa esperar para quien espera aburridamente ${ }^{4}$ Entonces, si el aburrimiento inaugura en el ser un dolor vinculante a la espera, lo que se pregunta realmente es: ¿ por qué a quien espera aburridamente la espera pareciera dolerle más? Ciertamente que no poseo ningún otro supuesto - además de la profunda reflexión a partir de la cita de Heidegger- que fundamente mi afirmación más que el acierto intuitivo de lo desagradable y doloroso que se siente esperar por aquello que le es vital a uno. Tampoco es descabellado asumir que casi todos podemos admitir, en cierta manera, lo doloroso que se siente el pasar del tiempo, como si el tiempo nos pasara por encima.

El objeto de la espera puede ser aquello que no está a la mano; pero como ya se dijo, más allá de ser un útil no disponible proyectado como eso inexistente por lo cual esperamos, es la disponibilidad misma la que se ausenta en la vida del aburrido. El aburrido no solo espera porque algo le sea disponible a la mano, sino que espera porque la disponibilidad misma le interpele y le es a la mano, esto es, disponible. En un sentido general, al aburrido nada se le presenta como disponible, como si este hubiera sido arrancado violentamente del azar teleológico del

4 Hacemos la diferencia entre quien se aburre esperando y quien espera aburridamente; la primera implica el tedio y lo latoso de esperar, mientras que la segunda implica un "quien" ya aburrido que espera algo en ese modo particular. En la primera, el aburrimiento se presenta como producto de la espera misma mientras que en la segunda el aburrimiento es un estado de ánimo previo a la espera. Obviamente, aquí se reflexiona a partir de la segunda. 
cosmos; es por ello por lo que su espera se basa en que la disponibilidad le vuelva a ser algo verdadero en su existencia.

El aburrido espera por salir de su aburrimiento, es decir, espera por un cambio que le provoque salir de lo mismo. El aburrimiento como lo mismo, implica la imposibilidad para el uno de pensarse a sí mismo como exterioridad y diferencia, esto es, de otra manera no aburrida. El aburrido espera por la disponibilidad de diferencia, pero esta diferencia no es la posibilidad de ser-otro, sino de ser-deotra-manera. Este ser-de-otra-manera se intuye como una salida del aburrimiento. Dice Cioran (2010) que "cuanto más constituye el hombre una existencia distinta, tanto más vulnerable se vuelve. Lo que no es puede herirlo; una nada es ocasión de perturbación [...]. Un animal que puede sufrir por lo que no es, he ahí al hombre" (p. 93). Dado que el aburrimiento es en el ahora en que se vive, o sea que constituye el modo de ser ahí dado (Dasein), se sufre por lo que no es, por no (ser) estar de otra manera y que este ahora aburrido ya no duela.

Quien espera aguarda; aguardar en la soledad del aburrimiento no es otra cosa que guardar-se uno mismo. Sin embargo, el aburrido que se des-espera no se guarda a sí y busca entre-tenerse para poder salir de su estado. Este entretenerse es pues una actividad que busca provocar que el tiempo se mueva. Entre-tenerse es procurar "ocuparse" en algo y que a la vez el tiempo fluya rápidamente en ello. Quien se entre-tiene se tiene a medias, pero en el a-guardar-se hay un retener de sí que es ganancia ontológica, aunque sea indeterminada y pura contingencia. Aguardar-se es (re)tenerse en plenitud. Curiosamente, desde el aburrimiento se eleva también una plenitud hostigadora que violentamente procura ser asumida y devorada. La misma se consuma al momento de auto-comprenderse como aburrido. Dicho de otra manera, asumir la frase "estoy aburrido" implica rendirse ante una nada que nos oprime y nos asfixia. Lo peor es que este rendirse no lleva consigo que esta nada dejará de ahorcarnos. Sentir el peso de la nada es igual de asfixiante que sentir todo el peso del mundo sobre uno. ¿Será esta la razón por la cual el aburrido aguarda, para tenerse plenamente y contrarrestar la fragmentación del ser que produce la insuficiencia vital del aburrimiento, a la vez que asume inequívocamente como suyo la sentencia "estoy aburrido"? Pero entonces, ¿cómo aguardar-se uno mismo puede hacernos posible ser-de-otra-manera, si el aburrimiento mismo se nos presenta como totalizante y hostigador, mientras que nos obliga a asumirlo plenamente? 
El fenómeno de la espera se da también como reconocimiento de una carencia, pues se siente que algo falta y se espera por ello. Esperar es saberse incompleto e insuficiente y a la vez percatarse de la total vulnerabilidad de la existencia ante el devenir. En el caso de la ausencia, de lo que falta, lo que hace al aburrido un ser carente es que su vida ha perdido significancia. Su existencia se ha desgastado. Lo desgastado está entonces incompleto, pero continúa íntegro. En este sentido, el aburrido que aguarda guarda de sí y de su integridad, pese a su desgaste. Se dice de una vez que al aburrido le es posible ser-de-otra-manera en tanto guarda y cuida de su integridad a pesar de ser-aburrido, esto es, a pesar de estar aburridamente desgastado viviendo una vida carente de sentido y significado. El desgastado ser del aburrido espera aburridamente ser-de-otra-manera que no le aburra. La imagen del aburrido que camina arrastrando los pies es el mejor ejemplo visual, para describir un cuerpo abatido por la insignificancia del mundo y de su propia existencia; se trata de una insuficiencia vital que justamente por arrastrar los pies no cae en lo totalmente nulo, sino que apenas muestra signos vitales desde su afección. Pese a todo, el aburrido se mueve lentamente y se desplaza.

Sobre lo que se desea aquí puntualizar acerca de la significatividad de la vida queda muy bien expresado en palabras de Manfred Kerkhoff(1997):

Todas las referencias juntas se llaman significatividad. Al ser-en-el-mundo no lo constituye solamente un estar, sino un comprender, un estar familiarizadocon. El existir consiste en este comprender y se comprende a sí mismo en él: aquello con lo que nos encontramos alrededor está interpretado como apropiado o inapropiado, y en este interpretar apropiador el ser-ahí se es significante, se le hace a sí mismo comprensible su existir como un ser-para, como significativo, esto es: perteneciente a la estructura de todo lo que se encuentra en esa forma del para-algo, del formar-un-todo que tiene significado. Sin tal significatividad no descubriríamos siquiera lo mundano como familiar; nuestro significar "crea" las cosas como mundanas, como formando un todo de servicio (p. 84-85).

La insuficiencia vital que se viene mencionando se fundamenta en el carácter significativo de la vida, cuando se percibe una deficiencia en la significatividad del existir. En un sentido hermenéutico, la insuficiencia vital es a lo que nos referimos cuando describimos la afección que padece el aburrido. El aburrido siente 
una relación insuficiente con el mundo a nivel de significado o, siendo más preciso, siente una insuficiencia en cuanto a su significancia. El mundo ya no lo estimula a tener una existencia significativa, tampoco este emplaza su voluntad a una búsqueda activa de significancia. Para el aburrido, el mundo no invita a nada. A esta pérdida de estímulo que causa la insuficiencia vital la llamamos inapetencia, porque no solo se hace referencia a la ausencia de estímulos, sino que la inapetencia deja manifiesto también que, aunque haya estímulos, estos no son ya de $m i$ interés. Inapetencia es pues estar vacío de interés.

En cuanto a la espera, la insuficiencia vital manifiesta el sentimiento de añoranza de lo que no es, pues el aburrido sufre por lo que no es en su tiempo. Como ya se dijo, aquello que no es, es el "objeto" de la espera; y la insuficiencia en este caso es no ser suficiente con lo que se es en el ahora. Entonces, considerando que quien espera aburridamente siente más el dolor del tiempo, y que su dolor está fundamentado justamente en la espera misma, se dice concretamente que tal espera es por el "regreso" de la significatividad de la vida, esto es, se espera por vivir significativamente. Si consideramos lo que afirma el filósofo Lars Svendsen (2013), que "el aburrimiento puede ser entendido como una molestia que comunica que la necesidad de significado no está siendo satisfecha” (p. 30), se puede afirmar en un sentido general que quien espera aburridamente espera por restablecer una relación significativa con el mundo y con la vida misma; y si el aburrimiento es a causa de la falta de significancia, se asume entonces que si esta es restablecida el aburrimiento se disipará.

Pareciera quedar mucho más claro el asunto que se propuso al principio de este escrito, que proponía que el aburrimiento puede ser entendido como aquello que da paso al dolor existencial mediante la espera, ya que el aburrido espera por el preciso momento de algo que, presume, disipará su aburrimiento. No se espera por cualquier cosa que nos entre-tenga y nos estructure de nuevo en el fluir del tiempo cronológico (histórico), sino por algo cuyo acontecer es el propio acontecer de lo histórico. Claro que todo acontecer es histórico en este sentido, en tanto cada interpretación de lo que acontece inaugura un discurso ( $\lambda$ ó $\gamma \circ$ ) en el existente. Pero de lo que aquí se trata realmente es del acontecer de la posibilidad misma, esto es, de la posibilidad de ser de otra manera.

Aunque se haya podido aclarar un poco la cuestión de aquello por lo que se espera, aún queda a un lado el sentido kairológico de esta espera, lo que implica 
que quien espera no puede perder de vista que, aunque pueda o no tener alguna idea de aquello por lo que se espera, ningún pronóstico le es fiable o confiable, tan siquiera admisible. Aquello por lo que se espera continúa siendo indescifrable en el sentido de que su temporalidad no está regida por cifras, esto es, número o extensión, mucho menos duración. El carácter tempestivo del kairós (kaıpós) remite a la llegada de lo absoluto en el tiempo. Pero en este caso, eso absoluto se manifiesta como la indeterminabilidad esencial de la espera; pues no hay nada que comunique la cercanía o la lejanía de aquello por lo que se espera. Como ya se mencionó, este aguardar kairológico es el vaticinio del mutuo coincidir entre aquello que en sí mismo lleva su propio ritmo con el ritmo de mi ser aburrido en el mundo. Entonces, se puede afirmar que el aguardar kairológico se expresa en la absoluta indeterminabilidad de la espera; y, a su vez, es lo que produce el dolor existencial, ya que quien espera aburridamente el momento justo que podría restablecer la significatividad de su vida en el mundo se encuentra suspendido sobre el vacío insignificante, y a su vez radical, del todavía.

Citando nuevamente a Kerkhoff (1997):

Se trata del poder autónomo de los sucesos, de lo que ocurre sin o contra nuestros planes, pero a veces para nuestro bien. Que se llame este factor anónimo y misterioso el "qué fáctico", Dios, lo eterno, el espíritu absoluto, natura naturans, el evento del ser, siempre se trata de algo fuera de nuestro poder y prever, algo azaroso, fatal, de carácter extrahumano que si coincide oportunamente con un instante que hemos escogido como apropiado para algo, sería lo más grande que podría ocurrir; es lo que a pesar de todo esperar y estar-preparado, llega inesperadamente y, apenas llegado, ya se ha ido (p. 89).

Esto significa entonces dar cuenta de la osadía de esperar lo inesperado. Esto, más que inverosímil o contradictorio, es reflejo del sentido absoluto y desproporcionado del kairós; desproporción que siempre apunta hacia lo sublime. Este aguardar kairológico es entonces una sublimación del todavia que rige todo acontecer, ya que el fenómeno de la espera se da en ese momento trascendental (o trascendente, todo depende desde dónde se mire) que llamamos ahora. Por un lado, se manifiesta como ahora-tiempo, localizado entre lo que ya fue y lo que será; y, por el otro, se manifiesta como ahora-vivencia, localizado en el vértice mismo del instante vivido. A continuación, se propone una aclaración de cómo 
se da esta radicalización del todavía en el ahora-tiempo y en el ahora-vivencia, y de cómo se relaciona esta experiencia con la espera y el dolor.

\section{Kairós doloroso}

Quien espera aburRidamente sufre el dolor del tiempo, pues el fenómeno de la espera revela una interferencia entre nuestro tiempo y el tiempo de ser de aquello por lo que esperamos. Es justamente esta interferencia, manifestada como un no-coincidir, lo que duele en el tiempo. Anteriormente se dijo que el aguardar kairológico es el vaticinio del mutuo coincidir entre aquello que en sí mismo lleva su propio ritmo con el ritmo de mi ser en el mundo. Esto puede implicar que el sentimiento de espera surja como la comprensión o internalización de la asincronía existente entre los elementos que configuran el devenir de lo real. La espera se presenta como reflexión negativa de aquello positivo que es su objeto. Reflexión negativa, porque no es (aún), y es positiva porque, aunque indeterminada, se objetualiza en la idea de lo que puede ser. Se objetualiza, pero no se cosifica. La relativa y aparente inconexión entre nuestro tiempo y el tiempo de las cosas refleja el carácter kairológico en tanto cada cosa, autónoma la una de la otra, representa su propia medida en el flujo contingente de todo lo que es; además de remitirnos a una temporalidad cualitativa dada como la mezcla oportuna, por vía de la simultaneidad, entre los distintos elementos que conforman lo que hay.

El preciso momento de las cosas nos deja aburridos y adoloridos en nuestro propio tiempo, mientras todo lo demás ocurre. Quien espera aguarda por algo que no es sin tener la más mínima duda de ello. Pero contrario a la fe, que puede ser entendida o asumida como arrojarse al vacío, quien espera se convierte en el vacío mismo; esto sucede así a medida que el que espera aguarda silenciosamente a que algo le sea arrojado. En la espera se suprime cierta voluntad, y un esperar quieto e involuntario hace del aburrido, además de carente, doliente: "el sereno esperar se mezcla con angustia” (Kerkhoff, 1997, p. 91) y el aburrimiento como el dolor del tiempo detenido es doble pérdida, pues cuando el tiempo del aburrido se detiene, se detiene también el porvenir del momento preciso. En el todavía se detiene el transcurrir del tiempo, lo que agudiza la crisis de sentido y la inapetencia que vive el aburrido en su insuficiencia vital. Jorge Reichmann (2011) dice que: 
Sólo somos capaces de dar sentido a nuestros actos y nuestra vida mediante su inserción en el tiempo como duración, en contextos de acción que se despliegan a lo largo del tiempo. La degradación del tiempo en sucesión de momentos inconexos nos sume en un sinsentido invivible (p. 38).

La cita anterior nos lleva a la premisa de que el aburrimiento ontologiza ese tiempo detenido de la espera; por esta razón, el todavía como "lugar" de la espera adquiere el carácter existencial de una discontinuidad irresoluble, pues el kairós absoluto de la espera arroja al aburrido al todavía donde el transcurrir del tiempo ha sido sustituido por la imposibilidad de duración y por la nuda existencia. Este todavía posee dos modos primordiales: por un lado, se da como el todavía no en su aspecto represivo de aún no, en la manera de un ahora-tiempo. Por otro, se da como atestación de lo todavía operante, esto es, aquello aún presente que adecua y viabiliza un ahora-vivencia. En su doble modulación, el todavía es una forma radical y extrema de la no-duración asumida y proyectada hacia el mundo desde el fenómeno de la espera. El todavía es radical y extremo, precisamente porque transforma la percepción temporal de nuestra existencia en la nulidad del transcurrir como punto abrupto de la espera y del aburrimiento, como agravante anímico de la forma en que se da esta espera. Por esta relación extrema fundada en el no transcurrir hablamos pues de un aburrido in extremis.

Este aburrido in extremis experimenta fácticamente el todavía no en la ilusión de pensar más allá del ahora-tiempo en el que se encuentra aburrido. En este sentido, toda ilusión de posibilidad objetivizada se da en esta modalidad, pues pensarse más allá del aburrimiento del ahora es un pensarse de otra manera determinada (pasado o futuro) como no aburrida. Pero esta misma otra posibilidad es lo que se nos niega en el aburrimiento, cuando el tiempo mismo se nos presenta como todavía no, es decir, como un "todavía no saldrás del aburrimiento". En este sentido, el ahora-tiempo puede ser pensado como límite y también como limitado; límite entre lo que fue y lo que será, y limitado por su virtual no-duración. El entre es aquí punto de división y no de intercambio, o sea que no es ni lo uno ni lo otro, mucho menos un punto convergente entre pasado y futuro, por así decirlo. Dado que aquí se muestra un ahora-tiempo aburrido, es también posible argumentar lo limitado de este ahora-tiempo en cuanto a su significatividad, esto es, su limitada significancia en cuanto a lo que reprime. El entre-tiempo de la insignificancia es un ahora que funge como base anímica para idealizar el pasado y 
el futuro, pues genera la tácita insignificancia de estas otras dimensiones. Ya que estas ilusiones de pasado o futuro son formadas desde un entre-tiempo presente insoportable, que a su vez proyecta esa insoportabilidad en sus idealizaciones, quedan de esta manera todas las demás dimensiones -pasado, presente y futurosuspendidas en la tentativa existencial que se manifiesta en la represión del aún no, pues lo que aún puede ser, aun sin ser, ya es caduco.

Por otro lado, la modulación de lo todavía operante se expresa en la manera en que el aburrido in extremis, a pesar de su aburrimiento, no está totalmente nulo, sino que aún continúa siempre operante en el ahora-vivencia; y opera en tanto aún hay algo del individuo ahí donde ejerce su presión la insuficiencia vital y el doloroso aguardar kairológico. En otras palabras, el aburrido in extremis asume esta modulación de lo todavía operante como la vivencia (Erlebnis) máxima de su eventualidad como existente, ya que se intercambia el riesgo de recuperar la posibilidad que se le niega en el aburrimiento por poseer su contingencia. Ya poseyéndola, no queda pues sino afirmarla. Asumirse en el ahora-vivencia conlleva renunciar a la temporalidad en tanto duración de la apariencia para sumirse en el vértice mismo de ser lo que aparece, o, mejor dicho, ser eso mismo que aparece. Mientras se destaca la horizontalidad de fluir de un antes a un después en el ahora-tiempo, el ahora-vivencia tiene la base de su verticalidad en el vertiginoso instante. Esto implica que aquello que es en el ahora-tiempo es aquello que siempre llega a ser entre pasado y futuro, versus el ahora-vivencia que siempre es un viviente en devenir. En este sentido, el ahora-vivencia que se despliega en lo todavía operante patentiza ontológicamente una temporalidad arritmica en la topografía del tiempo como horizonte existencial, esto es, la arbitrariedad del devenir no solo como principio esencial de lo real, sino como esencia anímica del aburrido in extremis en esta modulación.

El kairós que hace presencia en el aguardar kairológico no solo es absoluto, sino que también es ineludible. Esto puede ser interpretado como el vérselas obligado del aburrido in extremis a rendirse ante el tiempo muerto de la espera. Hablamos pues de un kairós doloroso 5 . Esta abrupta discontinuidad, que representa

5 “[...] kaıpós negativo, es decir: doloroso o desgarrado" (Kerkhoff, 1997, p. 33). "El kairós tiene también un carácter negativo (akairía, destiempo, fatalidad, muerte, accidente, mala suerte)” (Rojas Osorio, 2001, p. 71). 
el aguardar kairológico para el aburrido, se puede asumir de dos maneras, a su vez vinculadas con las dos modulaciones del todavia: de manera ontológicamente fulminante o de manera ontológicamente patética. La primera se acopla mejor al ahora-tiempo y a su liquidación, ya que se le da fin a la existencia si no se quiere continuar esperando en lo que se asume y experimenta como un entre tiempo ( $\mu \varepsilon \tau \alpha \xi i$ - metaxý). Mientras que la segunda se acopla al ahora-vivencia como un (a)pathos existencial' , porque se fundamenta anímicamente en el vértigo de la indeterminabilidad para su autocomprensión existencial de lo azaroso de la contingencia misma que uno es. Entonces, si el sentido temporal del todavía al que nos arroja el aguardar kairológico se da en el ahora-tiempo y el ahora-vivencia, su sentido ontológico tiene lugar en estas maneras -fulminante o patética- de darse y asumirse fácticamente en su comprensión.

Antes de proseguir, queremos condensar lo que se ha dicho hasta el momento. Comenzamos con el argumento de que el aburrido espera por aquello que lo "sacará" de su aburrimiento, esto es, que se le devuelva la significatividad a su existencia mediante el restablecimiento del sentido a su vida. El esperar del que aquí se habla no es un esperar cualquiera, pues no hay en él ningún aspecto que pueda ser calculado ni pronosticado. Este esperar es kairológico, pues remite a un momento justo o preciso, a un coincidir del devenir que configura toda realidad. La esencia de este aguardar kairológico recae justamente en que lanza al aburrido a la radical y extrema temporalidad del todavia, donde esta es asumida como un ahora-tiempo (todavía no) o un ahora-vivencia (todavía operante). La primera es la insoportabilidad del entre-tiempo y la segunda la afirmación de la contingencia. Como ya se dijo, estas dos modulaciones del todavía son comprendidas ontológicamente por el aburrido como fulminante o patética; ello por la sensación invivible e insignificante del entre-tiempo o por la vertiginosidad de la contingencia asumida como un (a)pathos. En su extrema radicalidad, el aburrido in extremis manifiesta la comprensión ontológica de su espera de manera igualmente extrema. Aquí llamamos aburrido in extremis suicida a la manifestación ontológicamente fulminante y aburrido in extremis anarco a la manifestación ontológicamente patética.

6 (A)pathos por la apatía de aburrido. 
Si bien Heidegger contempla al aburrimiento profundo como la forma esencial para comprender el aburrimiento en su carácter general, y por ende, la esencia del tiempo mismo, con la distinción de aburrido in extremis intentamos aclarar la manera de darse fácticamente esa "profundidad" en la vida insoportable e invivible de quien espera aburridamente. No se debe olvidar que, además del aburrimiento, esta reflexión trata sobre el fenómeno de la espera vista como un aguardar kairológico. Entonces, no solo es importante para nosotros la profundidad del aburrimiento, sino la magnitud dolorosa que este aguardar kairológico principia en la existencia.

\section{El aburrido in extremis: suicida y anarco}

EL ABURRIDO IN EXTREMIS es el modo de ser del aburrido al cual estamos adscribiéndole (si bien no prescribiéndole) la afección aquí descrita y desarrollada fenomenológicamente. Mencionamos antes que por lo extremo y radical de la temporalidad vivida fácticamente en el todavía y sus modulaciones, este aburrimiento se torna in extremis. Pero además de sus modulaciones referentes a la temporalidad, esto es, el ahora-tiempo y el ahora-vivencia, este todavía posee unos aspectos referentes a su comprensión ontológica igualmente extremos y radicales. A estos modos de comprensión ontológica los llamamos fulminante y patético, los cuales hacen de la vida fáctica del aburrido in extremis un suicida o un anarco, respectivamente. El aburrido in extremis suicida responde, primeramente, a la insoportabilidad del entre-tiempo (metaxý), mientras que el aburrido in extremis anarco se da como afirmación de la contingencia de la existencia en su carácter total, general y unificador. Esto no como una plenitud o armonía trascendental, sino todo lo contrario; como el caos originario que se desdobla desde un ocultamiento impensable e impresentable hacia su aparecer como presentabilidad, propiciando así la existencia. Pero antes de proseguir de lleno en describir al aburrido in extremis suicida y anarco, aclaremos primero el aspecto ontológico de su radicalidad y extremidad.

Además del estado anímico en relación con el tiempo mismo que somos, esto es, la existencia, para esta reflexión se ha tomado también como fundamental para el aburrimiento la relación insuficiente de esa existencia con el mundo donde existe y la insignificancia de esta vida del existente. Así se muestra que la 
modalidad de aburrido in extremis no pretende ampliar el aburrimiento profundo de Heidegger, ni tampoco contrariarlo, solamente integrar las categorías de insuficiencia e insignificancia para que sea entonces posible una aprehensión de su intensidad y magnitud, y no solamente de su "profundidad" y "resonancia".

Hemos dicho que queremos prestarle especial atención al cómo se sufre el aburrimiento en su facticidad. Heidegger habla de la cotidianidad del ser aburrido en el aburrimiento profundo pero nunca se refiere expresamente a la vida vivida por el aburrido, ni siquiera en su propia terminología, entiéndase, la vida fáctica. Si bien Heidegger propone una modulación trascendental (más allá) con la forma de ser del Dasein en el aburrimiento profundo, lo que se muestra del aburrido in extremis es una modulación trascendente (más acá) hacia su vida fáctica. En tanto "uno se aburre", esta indeterminabilidad de todo y de nadie del aburrimiento profundo, es algo que refiere a la Stimmung, en el sentido de que Stimmung también significa atmósfera. En cambio, el aburrido in extremis es algo relativo al sujeto en tanto individuo que enfrenta su vida fáctica a un mundo totalmente insignificante. Según Heidegger (2015), esta categoría de sujeto queda anulada en el aburrimiento profundo, o utilizando sus palabras: "estamos depuestos de personalidad cotidiana” (p. 179). A partir de esto decimos que, si el aburrimiento profundo es un temple anímico, esto es, un qué, el aburrido in extremis es, entonces, un quién templado al extremo. Un ser que vive sin tregua alguna la radicalidad y extremidad de su afección, esto es, la insuficiencia e insignificancia del aburrimiento. El aburrido in extremis es el quién de la insuficiencia vital.

En el aburrimiento extremo, la insuficiencia vital significa afección a nivel de la vida misma como proyecto. Se dice entonces que el anti-proyecto suicida es para acabar el tiempo que él mismo es y de esta manera renunciar al proyecto. Eliminándose a sí mismo del proyecto, no se elimina solamente el compromiso individual con el proyecto, sino toda voluntad de que el proyecto se lleve a cabo. Pues si bien se sabe que el proyecto continúa aun cuando el suicida ya no está, su acto de fuga es uno de renuncia total; tanto así, que le cuesta la vida. Mientras que en el anti-proyecto anarco, vemos que este implica acabarse a sí mismo en el proyecto agotándose ambos a la vez. En este sentido, "la naturaleza y la mente desgranan su ser en el devenir” (Rojas Osorio, 2001, p. 81), logrando así renunciar a sí mismo sin tener necesariamente que renunciar al proyecto. $\mathrm{Si}$ en efecto se considera la vida como proyecto, el aburrido in extremis, en cuanto a 
su existencia, posee una relación insuficiente con el mundo y una vida insignificante para sí mismo; se puede decir entonces que el aburrido in extremis es, en este aspecto de la vida como proyecto, un desproyectado. Pues tanto el suicida, que suicidándose se des-proyecta fulminantemente, el desvínculo y desarraigo del anarco en cuanto al proyecto hacen que este también se des-proyecte, pero apáticamente.

En lo referente a la espera y el proyecto, estos son conceptos que no se deben equiparar, pues la espera no debe representar la totalidad del proyecto, sino una parte de este. No hay espera tan importante como para que constituya la totalidad de un proyecto de vida, ni en este caso de un aguardar kairológico. No queda pues más que admitir que la espera es también paciencia, y en este sentido, nuestra conciencia del tiempo se ocupará de convertirnos a todos en pacientes. Así como en todo entretenimiento hay un aburrimiento queriendo ser sepultado sigilosamente, hay también en toda espera una paciencia implícita que no necesariamente es signo de imperturbabilidad, sino que proviene desde el dolor más inevitable, y por ende más intenso, a saber, el dolor de estar vivo. Dolor que, como sabemos -y el aburrido in extremis lo sabe aún mejor-, solo es suprimido con la muerte.

Retomemos pues las descripciones fenomenológicas de las comprensiones ontológicas del aburrido in extremis. La comprensión ontológicamente fulminante del todavia no se asume como tragedia en el sentido de Hölderlin de "lo eternamente cada vez"'. Aquí, lo visto como "eternamente cada vez" es el aburrimiento, pues recordemos que la represión ejercida por el todavía no representa la persistencia del aburrimiento en el ahora-tiempo, siempre el mismo; un presente que cada vez es ahora, siempre entre pasado y futuro. El ahora-tiempo se vive fácticamente como el ahora que es siempre y siempre entre, nunca otro. He aquí lo trágico, estar siempre en lo mismo. Estar siempre aburrido y esperando aburridamente. Para ello, la salida ontológicamente fulminante de lo mismo, por demás radical y extrema, es el suicidio. Para el aburrido in extremis el metaxý no trae novedad, solo des-espero. En este aspecto que tiene que ver con la espera aburrida,

7 "Hölderlin entiende que la tragedia no es meramente un acontecer temporal ni sobretemporal, sino más bien 'lo eternamente cada vez'. Lo trágico es un acontecer que tiene su tiempo propio [...]” (Rojas Osorio, 2001, p. 71). 
el suicida aparenta desesperarse. En este caso, el suicidio es el abandono absoluto del doloroso aguardar kairológico en el que se vive aburridamente, pues se suicida por negarse a ser un paciente aburrido. El verdaderamente desesperado no es aquel que con su queja constante ahoga al mundo con sus lamentos, sino aquel que desiste por completo de la espera y lo hace de manera radical. Se trata pues de aceptar la muerte antes que lo invivible del metaxý que, dentro de su insuficiencia e insignificancia, no lleva a ninguna parte.

Asumiendo ontológicamente el desfase de lo real como una espera dolorosa, el aburrido in extremis suicida se reprime del tiempo que es su propia existencia. En su insuficiencia vital, el suicida aniquila en él aquello que lo vinculaba brutalmente a su afección, la existencia del tiempo en sí mismo. Negada toda posibilidad en él, el aburrido in extremis suicida eligió no darse más al aguardar kairológico, decidió que su acto de desvincularse de la espera fuera uno verdaderamente radical, un acto de desvinculación ontológicamente fulminante. Harto y cansado de esperar poder ser de otra manera no aburrida, y dicha posibilidad negada en su totalidad, la espera se convierte en una tortura autoinfligida. Respecto a esperar lo inesperado, en el sentido de esperar lo incalculable del justo momento, no solo es el angustioso carácter del aguardar kairológico que aquí se discute, sino que, fácticamente hablando, involucra también una crueldad metódica, y por demás fundamental: dejar al tiempo ser solo por el morboso afán de que dicho tiempo sea. Es a esto justamente, a lo que el aburrido in extremis suicida se niega fulminantemente. "El suicida quiere ahorrarse tal esfuerzo, evita el confrontamiento con su ser-hacia, se hace 'culpable' como impotente de su propio ser" (Kerkhoff, 1997, p. 72).

En el aguardar kairológico, el aburrido in extremis se aborrece ${ }^{8}$ de su espera aburrida y se aleja con horror hacia su soledad más íntima, huye de la exterioridad del mundo que se le niega para situarse en su mayor debilidad, la interioridad de sí mismo. Decimos su mayor debilidad, pues en la insuficiencia vital en la que se encuentra, tanto su interioridad como su exterioridad son afectadas. Tanto la vida interior como la exterior son desagradables. El suicida, pues, no es tanto un desesperado como se dio a entender anteriormente; lo que ocurre con este es que no

8 Ambas palabras (aburrimiento y aborrecimiento -o aborrecer-) comparten raíz latina del verbo horrere: sentir horror, estar tieso o erizado, con los pelos de punta. 
siente lugar alguno en el mundo donde pueda esperar; esto es, no existe con quién. Uno es solo en su aburrimiento. También le es insoportable estar consigo mismo, ya que su propia inercia -estilo cadáver- le repugna. El aburrido in extremis se encuentra en una posición de abyecto total, pues le es imposible ser en el mundo y ser consigo mismo. El no-ser se le presenta como inminente y única resolución. No es lo mismo "ser" cadáver que no ser del todo9. Se puede decir que la última auto-comprensión por parte del aburrido in extremis suicida es: iya... no puedo ser!; a lo que le procede su inevitable muerte. Queda plasmado no solo el hecho de que la espera sea evidentemente una opción que se evade o se asume, sino que a la vez que se le presenta a uno tal situación, se convierte en un asunto desagradablemente ineludible e impostergable. Algo, como solemos decir, "de vida o muerte".

Así se muestra cómo una de las comprensiones ontológicas del aguardar kairológico se trata realmente de no esperar; ¿o será acaso haber esperado lo suficiente? Pero si fuera esto último, ya estaríamos hablando de lo que Kerkhoff llama el suicidio kairológico o la kairotanasia, pues lo que implica sería que "llegó" el momento preciso para desistir fulminantemente de la espera. En este sentido, el aspecto kairológico de la espera y su dolor se revierten en lo kairológico de ese momento en que el suicida da con su resolución y dice: iya... no puedo ser! Se dice pues, que el momento preciso ya no continúa siendo aquí aquello por lo que se esperaba, que era el regreso de la significatividad de la vida, sino que se reconstituye como eventualidad en el justo momento silencioso de ese último hastío del suicida. Ya no más.

Antes de entrar en la elaboración descriptiva del aburrido in extremis anarco, entonemos lo que se acaba de pensar sobre el suicida con estas palabras de Cio$\operatorname{ran}(2010)$ :

Estás inmóvil y esperas. Te estás esperando. Pero ¿qué vas a hacer contigo? ¿Qué te vas a decir, rodeado como estás de tanto no-decir? ¿Qué pasa a través

9 Tampoco es lo mismo pensarse como cadáver que verse a sí mismo como cadáver, ya que lo último implica una metáfora al concepto de autoimagen que se encuentra ausente en lo primero, esto por el hecho de que en el primer ejemplo se trata de capturar la idea de algo así como una autoconciencia del cadáver, lo cual es imposible saberlo, o al menos comunicarlo. Tal como dice Kant en su Antropologia, que "el pensamiento: no soy, no puede existir" (Kant, 2010, p. 76). Entonces, el verse como cadáver en el sentido de autoimagen es lo que repugna al suicida, aunque su acto suicida lo convierta justamente en un cadáver. Pero ya "siendo" cadáver, no-es. Ya no importa. 
del silencio? ¿Quién pasa? Es tu mal que está pasando a través de ti, fuera de ti, es una omnipresencia de tu misterio negativo. ¿Piensas en lo que quieres ser? Tus pesares no tienen futuro. Ni ningún futuro es tuyo. En el tiempo ya no tienes cabida; en el tiempo yace el horror. $\mathrm{Y}$ entonces te vas. Al marcharte te olvidas. Y en tu caminar eres otro y siendo, ya no eres (p. 27-28).

La comprensión ontológicamente patética, por su parte, transforma el desfase de lo real en arritmia, donde las rupturas y los saltos de todo tipo provocan lo múltiple. Esta arritmia no solo es temporal, sino anímica (ontológica); lo que produce que entre la existencia y el instante en que se vive no haya proximidad alguna, sino pura intensidad ${ }^{10}$. Dicha intensidad se manifiesta en la afirmación de la contingencia; afirmación de su instante existencial finito, plegado sobre y en sí mismo. Inevitablemente, esto anuncia también su contingente punto de desaparición, pues eso mismo que posibilita su despliegue posibilita también su agotamiento. En este sentido, el aburrido in extremis anarco vive una finitud intensificada, pues, como captador de la existencia en su carácter repentino, siempre está bajo amenaza de ser y actuar; esta es su exigencia incondicional. En otras palabras, tiene que lidiar con lo urgente, esto es, para lo que nunca "hay" tiempo. ¿Y qué es eso para lo que nunca "hay" tiempo? Es ese "yo" siempre-aburrido que muere calladamente, mientras todo lo demás ocurre. Soy yo-ahora (aburrido) con la realidad.

Aunque parezca aquí que hemos convertido el aburrimiento en otra cosa, de lo que se intenta dar cuenta es del impulso todavía operante a pesar de la insuficiencia vital. No debemos equiparar la vivencia que interpela al anarco por el hecho de existir con lo que se refiere a su vitalidad, pues por estar totalmente comprometida su vitalidad dentro de la insuficiencia del aburrimiento es posible justamente el aprehender de manera tal el tiempo-vivencia del todavía al cual queda lanzado el anarco en su aguardar kairológico. Valdría ahora la pena decir que el aburrido in extremis anarco, dentro de su insuficiencia vital, más bien se des-vive cada momento en sus vivencias. No hay ya en él, por así decirlo, una

10 “[...] El tiempo vivido nos penetra tanto, nos 'rodea' tan de cerca que no hay manera de distanciarse de él; por la misma razón, es imposible marcar la diferencia entre un estado (de la vida) y la transición a otro, ya que no hay, en tal fluir, pulsar, pasar, ningún lugar 'entre' dos estados que permitan algo así como la transición de un no-ser a un ser-tal” (Kerkhoff, 1997, p. 2). 
vitalidad constante, por lo que se ve obligado a hacerse y deshacerse en cada ahora-vivencia que se le confronta. En este aspecto, la ontología patética del anarco es ahistórica, en el sentido de que su constante hacerse y deshacerse desplaza lo histórico por la potencialidad del devenir. Respecto a este asunto recordemos que la temporalidad arrítmica del anarco no solo se interpreta como principio esencial de lo real, sino como esencia anímica de su anarquía.

Por esta falta de historicidad, el anarco se abre totalmente a la potencialidad del devenir, pero aunque aquí se resuelva toda contradicción fáctica en cuanto a su existencia, no se resuelve así su contradicción en cuanto a su vida fácticamente vivida. En otras palabras: el hecho de ya existir resuelve el dilema entre ser o noser de lo contingente, por eso es posible su afirmación, tal cual hace el anarco puesto que existe y es; pero no es así en cuanto a su vida fáctica entendida la misma como la multiplicidad de aconteceres de valor extrínseco con los cuales el individuo viviente se ve en necesidad absoluta de relacionarse, tanto afectivamente como racionalmente. Esto significa que al aburrido in extremis anarco le es imposible perderse, pues siempre termina dando consigo mismo en su aburrimiento. Le es imposible perderse en el sentido de que faltar a la exigencia incondicional de sus vivencias le es imposible, al igual que dejar de percibirse como un yoahora siempre aburrido y siempre insuficiente. Por su finitud intensificada, como se mencionó anteriormente, este se las ve siempre en riesgo de lo repentino, y tomando en cuenta su insuficiencia, estar siempre ante el riesgo de lo repentino es estar siempre en precariedad. En su anarquía ahistórica, donde cada instante se hace y se deshace ahí mismo en todo momento con él, el aburrido in extremis anarco no puede prescindir de su impulso primario y fundamental para hacer y deshacer. He aquí la afirmación existencial de su contingencia.

Por más arrogante que suene: depende de mí, de mi decisión, su xalıós es ahora o nunca: "La máxima tensión (de la existencia) resulta del fenómeno originario de que, lo que es eterno, solamente llega a ser por nuestra decisión: la decisión en el tiempo es el aparecer (histórico) de lo que somos atemporalmente" (Kerkhoff, 1997, p. 145) ${ }^{11}$.

11 Esta cita de Kerkhoff contiene, a su vez, una referencia a la página 906 de la obra Von der Wabrheit de Karl Jaspers. 
El aburrido in extremis anarco no busca entretenerse para así saciar su aburrimiento y disipar la espera, pero tampoco elije la muerte al igual que el suicida. Entonces, ¿en qué se diferencia la posición ontológica del aburrido in extremis anarco de un mero someterse al aburrimiento y a la espera? Para poder contestar, remitámonos primero a lo que implica la transformación del desfase de lo real en arritmia; que no es otra cosa más que la transformación del dolor del no-coincidir asociado al aguardar kairológico, en el dolor de la arritmia entendida como el carácter deviniente de lo real. Pues, si bien el primero se manifestaba como un dolor represivo y privativo de lo negado por el aburrimiento, pero "prometido" en la espera, el segundo es un dolor típico de vivir circunstancias vertiginosas aquí asociadas a la internalización ontológica de lo azaroso de la contingencia como algo característico y fundamental del estado de ánimo. Al haber reinterpretado de esta manera este dolor, la propia indeterminabilidad del aguardar kairológico queda subvertida en la indeterminabilidad de la vida misma; pues no habiendo algo específico por qué esperar, tampoco hay espera. Aquí, la indeterminabilidad de la espera no solo es subvertida, sino que es también superada; esto en el sentido de que la indeterminabilidad suprema -y la que le afecta al aburrido- yace realmente en aquel grosero silencio que diferencia lo vivo de lo muerto. Así pues, el anarco, estando en nada, lo tiene todo al filo de su contingencia. Está vivo. Insuficientemente vivo, pero así está bien.

Ya dicho esto, se procede a expresar que, tal cual el aburrido in extremis es un ser templado al extremo -y el suicida su modulación que decidió no-ser en tal extremidad-, el anarco es la modulación que optó por una contrafinalidad, la de hacerse expreso en cuanto a su insuficiencia vital, haciéndose y deshaciéndose en ella. Explicado en términos de su ahora-vivencia: "es el movimiento (en apariencia) desgajado de su referencia espacial y material y no refiriendo más que a mí mismo y mis estados anímicos" (Rojas Osorio, 2001, p. 76).

4. Vacío y de salida

EN LA ESPERA SE CORROE lo que en el aburrimiento se ha frenado previamente, esto es, la significatividad de la vida. Aquí se ha tratado siempre sobre alguien que espera aburridamente el devenir de dicha significatividad y no sobre alguien que se aburre esperando la llegada de alguna otra cosa. La diferencia que cabe señalar 
aquí consiste en que esperar aburridamente implica el mero estado de ánimo en el cual se da la espera; mientras que en aburrirse esperando, el estado de ánimo es un producto generado por la espera. Claro está que toda espera lleva consigo - de alguna manera- la tendencia al aburrimiento, pero en este sentido, no todo aburrido que espera lo hace por una vida significativa ${ }^{12}$. Hay quien vive tan entretenido u ocupado matando el tiempo que ni siquiera es consciente de lo aburrido y miserable que es su insípida vida. Saberse aburrido y buscar entretenimiento para disiparlo es una cosa (tal cual la niñez), pero estar siempre entretenido para no tener que lidiar con los vahos de un aburrimiento salvaje es otra (tal cual la adultez). Como también es diferente reconocerse aburrido en un mundo también aburrido y admitir tal extremidad anímica (tal cual aburrido in extremis).

Podríamos concluir diciendo que el aburrido in extremis sí sabe lo miserable de su existencia y del mundo que le traspasa. Tanto el suicida como el anarco saben que no hay escapatoria pero sí formas volátiles de evasión.

Sobre el suicida se pudiera seguir reflexionando y especulando, pero tal como dice Jean Améry (2005): “[...] cada vez que alguien muere por su propia mano, o intenta morir, cae un velo que nadie volverá a levantar, que quizás, en el mejor de los casos, podrá ser iluminado con suficiente nitidez como para que el ojo reconozca sólo una imagen huidiza" (p. 19).

Aquí, reconocemos, no ocurrirá lo contrario. Bastará con decir que no murió esperando, sino que se mató de aburrimiento.

Sobre el anarco, sin embargo, se dice, o más bien se aprecia, que en la sociedad contemporánea suele confundirse a este con un sujeto depresivo ${ }^{13}$. Pero este, más bien, sufre la nostalgia de lo inhóspito, ya que decide mantenerse en su trivialidad. Siempre y a pesar de todo, nunca "gracias a". El aburrido in extremis anarco está obstinado en la resistencia, cosa que muy probablemente comparta con el sujeto

12 Es la peculiar espera de la que queremos salir, de modo que se sugiere si quizás esta espera es el aburrimiento. Por último, resultó que la espera y el aburrimiento no son idénticos, sino que la espera puede tener ella misma el carácter de la aburribilidad, pero no tiene por qué (Heidegger, 2015, p. 131).

13 Es de notar que en nuestra sociedad contemporánea, donde la sobremedicación de drogas y fármacos antidepresivos es la orden del día, un quién que se mantenga abstemio de la medicación clínica de narcóticos muy bien puede considerarse como un a-narco; entiéndase, no-narcotizado por el complejo industrial de salud contemporáneo basado en el fármaco-capitalismo y la toxicomanía. 
depresivo. ¿A qué se resisten ambos? Algunos psicoanalistas ven en la depresión una forma de protesta.

Así, mucho de lo que se etiqueta hoy como depresión puede ser entendido como la antigua histeria, en el sentido de un rechazo a las formas presentes de autoridad y dominio. Cuanto más insista la sociedad en los valores de eficiencia y productividad económica, más proliferará la depresión como una consecuencia necesaria. De forma similar, cuanto más nos apremie la sociedad moderna a alcanzar la autonomía y la independencia en nuestra búsqueda de la realización, más adoptará la resistencia la forma del opuesto exacto de estos valores; colocará la miseria en medio de la abundancia. La depresión es, entonces, una forma de decir NO a lo que nos dicen que debemos ser (Leader, 2014, p. 18-19).

No olvidemos que su resistir es también un resistir desde su insuficiencia, y este resistirse es a un desabucio existencial. Se podría argumentar que este se resiste al mismo desahucio existencial del cual se libró, o el cual asumió violentamente el suicida. Pero contrario al suicida, quien abrazó la muerte en un acto filotanático, el anarco pareciera ser distanático, en el sentido de que guarda su espacio ante la muerte. Pero este es más bien adistanático ${ }^{14}$ activo, en el sentido de que, si bien no busca entretenerse, tampoco ahonda ni deja resonar su aburrimiento en el sentido heideggeriano (profundidad y resonancia). El anarco es adistanático activo por el hecho de que activamente se aferra a su estado anímico, pero no se fía de él. De este aferrarse pero no fiarse se despliega una sabiduría melancólica que muy bien sabe que esperar por el sentido de la vida no vale la pena, pero tampoco se anima a quitarse su insignificante vida. Su obstinación se encuentra anclada a su estado anímico, o mejor dicho, a su des-ánimo. Desanimado de la espera, desanimado de buscar entretenimiento, desanimado del suicidio y de la muerte, el aburrido in extremis anarco no quiere nada. Inapetencia extrema.

El suicidio pro-cura pero no cura, tampoco resuelve nada porque nunca hubo un problema en primer lugar. Este solo problematiza y resuelve toda la existencia

14 "Distanasia, cuando se tiende a alejar lo más posible la muerte y la vida se prolonga utilizando medidas extraordinarias, sin que haya esperanzas de recuperación. Adistanasia, cuando se decide no prolongar la vida, para lo cual se omiten medios y tratamientos que mantendrían vivo al paciente [...]. El término ortotanasia, se refiere a la justa relación entre la distanasia y la adistanasia (entre lo desproporcionado y lo proporcionado)" (Álvarez del Río, 2005, p. 123). 
en un acto fulminante. Contesta con un silencio eterno la pregunta proveniente de la boca más honesta. Por otro lado, el anarco dice: "quiero ser... Solo que no soporto estar". La pregunta para la que el anarco trata de ser respuesta es: ¿cómo ser donde no se puede ya estar? El suicida hace de su suicidio el justo momento, y así revierte el kairós de su espera en el de la eventualidad de su muerte; el anarco subvierte la indeterminabilidad de la espera en la indeterminabilidad de la vida misma, superando así la espera. De esta manera, la espera se dispersa, pero, ¿qué hay con el aburrimiento? Sigue ahí. Incólume. Sobre uno, en todas partes y para siempre. Se espere o se desespere, se suicide o se vuelva un anarco, de todos modos, el aburrido in extremis no se escapará nunca de morir aburridamente.

\section{Referencias}

Álvarez del Río, A. (2005). Práctica y ética de la eutanasia. México D.F.: Fondo de Cultura Económica.

Améry, J. (2005). Levantar la mano contra uno mismo. (Trad. M. Siguan \& E. Aznar). Valencia: Pre-Textos.

Cioran, E. (2000). Cuadernos (1957-1972). (Trad. C. Manzano). Barcelona: Tusquets Editores

Cioran, E. (2010). Breviario de los vencidos. (Trad. J. Garrigós). Barcelona: Tusquets Editores.

Heidegger, M. (2015). Los conceptos fundamentales de la metafísica: mundo, finitud, soledad. (Trad. A. Ciria). Madrid: Alianza Editorial.

Kant, E. (2010). Antropología. (Trad. J. Gaos). Madrid: Alianza Editorial.

Kerkhoff. M. (1997). Kairos: exploraciones ocasionales en torno al tiempo y al destiempo. Río Piedras: Editorial de la Universidad de Puerto Rico.

Leader, D. (2014). La moda negra: duelo, melancolia y depresión. (Trad. E. Corona). Madrid: Editorial Sexto Piso.

Reichmann, J. (2011). Tiempo para la vida: la crisis ecológica en su dimensión temporal. Bogotá: Taller de Edición Rocca.

Rojas Osorio, C. (2001). Del ser al devenir. Humacao: Museo Casa Roig/Universidad de Puerto Rico en Humacao.

Svendsen, L. (2013). A Phlilosophy of Boredom. (Trad. J. Irons). London: Reaktion Books. 